\title{
Current clinico-mycological trends of onychopathies in Casablanca
}

\author{
L Badaouiं, G Dabo, R Bensghir, I Halim, S Belyamani, M Soussi Abdallaoui, S Chiheb, K El Filali Marhoum \\ From International Symposium HIV and Emerging Infectious Diseases 2014 \\ Marseille, France. 21-23 May 2013
}

\section{Background}

Onychopathies in patients infected with HIV are dominated by onychomycosis. It is one of the early manifestations of HIV infection the purpose was to study the epidemiology, clinical manifestations and mycological profile of onychomycosis in HIV-infected individuals and to identify the other causes of onychopathies in this population.

\section{Methods}

A total of $88 \mathrm{HIV}$ infected patients, monitoring at Department of Infectious Diseases, were screened for nail involvement over a period of 3 months. Inclusion criteria: Patient who had do not receive any antifungal treatment were included.

\section{Results}

A total of 88 subjects were examined ( 45 men and 43 women); the average age were 41 years old. Abnormal appearing nails were present in 48 cases. Mycologic evidence of onychomycosis were present in 42 cases. The clinical presentation of onychomycosis was: distal and lateral subungual onychomycosis (47\%); white superficial onychomycosis (5\%); proximal subungual onychomycosis (21\%); total dystrophic onychomycosis (26\%). Toenail involvement was seen in 26 patients, fingernail in 11 patients while 5 patients had involvement of both fingernail and toenail. The various aspects noted were: Xanthonychia (19 cases), pachonychia (17 cases), onycholysis (7 cases), leuconychia (6 cases) and melanonychia (4 cases). The culture has allowed the confirmation of onychomycosis in $73.3 \%$. Among the 16 positive dermatophytes cultures, Trichophyton rubrum was isolated in 12 cultures, Trichophyton interdigitale in 3 cultures, and Trichophyton Mentagrophyte in one case. Of the 12

Ibn Rochd University Hospital, Casablanca, Morocco non-dermatophytic cultures, Candida albicans and Candida dubliensis were isolated in 4, Candida parapilosis in 2 while Trichosporon spp., and Penicillium spp. in each one.

\section{Conclusion}

The prevalence of onychomycosis was $48 \%$. It seems that the incidence of NMD is higher in the HIV patients compared with immunocompetent population.

Published: 23 May 2014

doi:10.1186/1471-2334-14-S2-P97

Cite this article as: Badaoui et al:: Current clinico-mycological trends of onychopathies in Casablanca. BMC Infectious Diseases 2014 14(Suppl 2):P97.
Submit your next manuscript to BioMed Central and take full advantage of:

- Convenient online submission

- Thorough peer review

- No space constraints or color figure charges

- Immediate publication on acceptance

- Inclusion in PubMed, CAS, Scopus and Google Scholar

- Research which is freely available for redistribution
() Biomed Central 